\title{
PARADOXOS DA EDUCAÇÃO NATURAL NO ÉMILE DE ROUSSEAU: OS CUIDADOS DO ADULTO
}

\author{
Claudio Almir Dalbosco*
}

RESUMO: O artigo trata do conceito de primeira infância em Rousseau, buscando esclarecê-lo mediante a análise do modo como Rousseau define os cuidados do adulto dispensados à supressão das necessidades da criança. Procura mostrar também que a definição deste conceito e o tratamento oferecido às dificuldades a ele subjacente dependem, em última instância, da inserção da própria temática dos cuidados no contexto normativo mais amplo da educação natural. O traço principal de tal contexto normativo repousa na idéia da liberdade bem regrada como diretriz do caminho natural, ao qual o processo formativo-educacional da criança deve ser conduzido. A definição dos cuidados do adulto conduz Rousseau à percepção de que estes só podem ser exercidos pedagogicamente com base no caráter aporético da educação natural, o qual se desdobra em três pólos tensivos.

Palavras-chave: Educação natural. Primeira infância. Cuidado adulto. Necessidades da criança. Liberdade.

\section{Paradoxes of the natural education in Rousseau's Émile: ADULTS' CARE}

ABSTRACT: This paper deals with the concept of first infancy in Rousseau in order to clarify it through the analysis of the way Rousseau defines the care adults devote to suppressing children needs. It also seeks to show that the definition of this concept and the treatment offered to the underlying difficulties ultimately depend on the insertion of the very theme of care in a broader normative context of natural education. The main feature of such a

Doutor em Filosofia e professor do Curso de Filosofia e do PPG em Educação da Universidade de Passo Fundo (UPF/Rs). E-mail: vcdalbosco@hotmail.com 
normative context rests on the idea of well ruled liberty as a guide to the natural path on which the educational shaping process should take place. The definition of adults' care leads Rousseau to realize that this care can only be exercised pedagogically on the basis of the non-poetic character of natural education which unfolds into three tensive poles.

Key words: Natural education. First infancy. Adult care. Child's needs. Liberty.

\section{Introdução}

conteúdo da educação natural esboçado por Rousseau no primeiro livro do Émile e dirigido à primeira infância é marcado pela tensão entre as necessidades da criança e os cuidados do adulto. ${ }^{1}$ No presente ensaio, buscando abordar tal tensão pela ótica dos cuidados do adulto, oriento-me pelas seguintes questôes: $\mathrm{O}$ que significa propriamente o cuidado do adulto no primeiro livro do Émile? Que aspectos precisos o caráter aporético da educação natural assume aí? Pretendo tratá-las amparando-me na hipótese de que, ao perceber a insolubilidade de algumas dificuldades que surgem da relação educativa entre adulto e criança, Rousseau não tem alternativa senão buscar contorná-las e tal contorno, delineado em três pólos tensivos, é a principal característica de seu projeto de educação dirigido à primeira infância.

Para dar conta tanto da problemática como da hipótese acima anunciadas reconstruo, em primeiro lugar, em quatro argumentos principais, o modo como os adultos devem exercer seus cuidados. $\mathrm{Na}$ seqüência, concentro-me em precisar os três pólos tensivos que sustentam o caráter aporético da educação natural. Com isso, penso poder oferecer, em largos traços, uma idéia do projeto rousseauniano de educação natural voltado a balizar os cuidados do adulto.

A relação entre mãe e bebe

O primeiro argumento importante apresentado no primeiro livro do Émile a favor da tese de que a criança precisa ser considerada em seu próprio mundo é construído por Rousseau, a partir da análise da relação entre a mãe e o bebê, considerando o ato da amamentação 
como constitutivo do primeiro entrelaçamento afetivo e social do bebê. ${ }^{2}$ Neste sentido, ele atribui valor significativo à amamentação, partindo do princípio, socialmente aceito em sua época, de que é a mulher (podendo ser a mãe ou mesmo a ama de leite) que deveria se ocupar intensivamente com a criança em sua primeira infância. $\mathrm{O}$ critério básico adotado para sustentar tal princípio é a importância que o leite materno desempenha no desenvolvimento da criança. Não chegou a pensar em situaçôes - hoje normais ao mundo ocidental contemporâneo, inclusive com o amparo de leis trabalhistas -, nas quais é o pai que fica em casa e se ocupa diretamente com a criança pequena, enquanto a mãe sai para o trabalho; ou, ainda, naquelas em que a criança fica sozinha em casa, apenas com a companhia da TV ou é levada para escolas de educação infantil, enquanto o pai e a mãe saem para o trabalho. Independente disso, Rousseau desenvolve uma argumentação firme na direção de mostrar a importância do leite materno para o desenvolvimento saudável do bebê. Assim afirma ele:

Mas que as mães concordem em amamentar seus filhos e os costumes reformar-se-ão sozinhos, os sentimentos da natureza despertarão em todos os corações; o Estado se repovoará. E este ponto, tão-somente este ponto, vai tudo unir. A atração da vida doméstica é o melhor contraveneno para os maus costumes. (OC IV 258; 1992, p. 21) $)^{3}$

Com a preocupação pedagógica de que o adulto não deve projetar verticalmente sua postura no mundo da criança, Rousseau pretende evitar a intromissão excessiva do adulto e atribuir papel importante aos pais e à família, no sentido de proteger a criança contra a invasão precoce e prejudicial da agressividade social no mundo da criança. Ele pretende evitar aí, na verdade, a "colonização adulta" do mundo da criança e, com isso, evitar que esta se transforme apenas em província ou apêndice do mundo adulto. Mas, por outro lado, considerando que não se pode e não se deve isolar completamente a criança do mundo adulto e nem do convívio social mínimo, a questão é como protegê-la desta colonização sem isolá-la. Justamente aí reside uma das tarefas centrais da educação natural, a saber, a de pensar e preparar o ingresso progressivo da criança na sociedade, evitando que tal ingresso signifique, ao mesmo tempo, a desfiguração do mundo infantil. A sutileza desta tarefa consiste no fato de que ela deve ser preparada pedagogicamente, de tal forma que possa proteger socializando a criança, evitando com isso que ela seja tratada desde o início só como um pequeno adulto. 
$\mathrm{O}$ modo como são exercidos os cuidados do adulto em relação às crianças, na primeira infância, torna-se questão decisiva para saber a intensidade e a qualidade da intervenção do adulto no mundo da criança. Neste contexto, Rousseau considera, como vimos, a constituição familiar e o papel dos pais como dois aspectos indispensáveis contra os maus costumes e como forma de preparar a criança contra uma educação viciada. O que está em jogo, em sua crítica, é o abandono da vida familiar, indispensável à educação das crianças, em nome de uma vida social baseada nas aparências e na representação dissimuladora. Os próprios adultos se deixavam seduzir pelo canto da vida em salóes e pela vida pública artificial, na mesma proporção em que se desinteressavam pela família e pela educação de seus filhos ou entregavam-na exclusivamente aos cuidados de terceiros. Frente às exigências impostas por uma forma de vida baseada na representação que os próprios adultos faziam de seu mundo, tomando como referência basilar a imagem que os outros deles mesmos faziam, a preocupação central de Rousseau era proteger o mundo da criança contra o artificialismo e a dissimulação das relações sociais provocadas pelo "caráter espetacular" do mundo adulto. ${ }^{4}$

O projeto de uma educação natural exige, por isso, uma participação efetiva dos pais na educação dos filhos, pois, para Rousseau, uma das formas de solidificar a "voz da natureza" na formação da criança, contra a artificialidade reinante na sociedade, é a de fazer valer a "voz do sangue", no sentido de fortalecer hábitos naturais por meio dos cuidados e da proteção exercidos pelos pais. O pressuposto desta posição é que a vinculação afetivo-paterna com a criança, orientada por aqueles princípios da educação natural que atribuem sentido normativo ao modo como os cuidados adultos devem ser exercidos, constrói um núcleo interno importante à formação progressiva da identidade da criança que lhe ajudaria na resistência futura contra os malefícios oriundos do caráter de representação artificial das relações sociais do adulto. $\mathrm{O}$ que pode ser objetado de pronto a esta linha de argumento de Rousseau é que os próprios pais, embora disponham neste caso de uma vinculação afetiva com seu filho, mais do que qualquer outro adulto, também não deixam de ser eles mesmos adultos que vivem em sociedade e, nesta condição, estão expostos a todos os malefícios oriundos da configuração social.

O não envolvimento dos pais na educação de seus filhos resulta no rompimento da educação natural, o qual se manifesta de duas maneiras bem definidas. Primeiro, na omissão de suas responsabilidades. 
No caso específico da mãe, quando se recusa, por razões estético-sociais, a amamentar o bebê e o entrega a uma ama de leite. Segundo, no caso extremo, quando os pais depositam excessivos cuidados à criança, isolando-a do mundo adulto. Qualquer uma dessas formas de rompimento é considerada muito prejudicial ao desenvolvimento da criança. Neste contexto, os cuidados do adulto tornam-se decisivos, tendo que se evitar tanto uma intervenção vertical constante como uma proteção excessiva. Tal equilíbrio da intervenção do adulto deve ser encontrado por meio do princípio pedagógico da educação pelas coisas, o qual é o segundo argumento decisivo empregado por Rousseau no primeiro livro do Émile para regular os cuidados do adulto.

\section{O princípio da educação pelas coisas e a insuficiência do contrato pedagógico}

Como se vê, o princípio pedagógico da educação pelas coisas, como segundo argumento, torna-se decisivo ao conteúdo da educação natural. Mas o que entende Rousseau por tal princípio? O problema pode ser formulado ainda de modo mais claro da seguinte forma: se o conteúdo da educação natural dirigido à primeira infância depende, em grande medida, do modo como os cuidados adultos são exercidos, temos aqui, nestas passagens iniciais do primeiro livro do Émile, a indicação de que o cuidado assume a forma de um procedimento pedagógico amparado na educação pelas coisas. A questão consiste, precisamente, em saber o que significa cuidar da criança, educando-a pelo exemplo das coisas.

O princípio pedagógico da educação pelas coisas pode soar hoje como uma expressão em desuso. No entanto, seu sentido atualizado pode estar sintetizado, por exemplo, na idéia da educação pela experiência. Mas é preciso ter claro que Rousseau, ao associar o conceito de experiência - entendendo-o mais amplamente, não só no sentido epistemológico que a tradição empirista lhe conferiu, mas também como esfera do agir humano em sua dimensão ético-pedagógica - ao princípio pedagógico da educação pelas coisas, quer dizer com isso que o ponto de partida do ato educativo precisa levar em conta o mundo do educando, com seus respectivos limites e potencialidades (disposiçōes naturais). Neste sentido, o princípio da educação pelas coisas deve substituir, sobretudo na primeira infância, a intervenção discursiva (verbal) vertical do adulto. 
Para esclarecer o próprio sentido dado por Rousseau a este princípio pedagógico, nada melhor do que recorrer ao seu clássico exemplo do vidro quebrado da janela. Embora tivesse sido prevenida, antecipadamente, de que não deveria quebrar os vidros da janela, mesmo assim, a criança termina por fazê-lo. Diante deste fato, Rousseau aconselha ser muito mais educativo: em vez de fazer um longo discurso à criança e consertar logo em seguida o vidro quebrado, não dizer nada a ela, mas também não consertá-lo. Assim, ao passar frio, a criança aprenderia, através da experiência com as coisas (no caso, com o vento gelado que entra em seu quarto), a cautela necessária para agir em outras situações semelhantes. Somente quando ela vier a protestar em razão do frio é que então a fala do adulto começaria a ter eficácia. Este exemplo mostra a importância da sensibilidade pedagógica do adulto em identificar claramente a situação - saber exatamente do que se trata no momento -, ter paciência para agir na hora certa e, sobretudo, agir com firmeza, mas sem perder a serenidade. Senso de observação, paciência, firmeza e serenidade parecem ser, neste caso, qualificativos do princípio da educação pelas coisas.

A educação pelas coisas deve substituir os longos discursos, muitas vezes moralizantes e agressivos dos adultos! Com isso, temos que a ênfase na educação da primeira infância não recai sobre a educação discursiva e, por isso, também não pode ser levada a diante, de modo direto e exclusivo, pela negociação argumentativa do adulto com a criança. Considerando-se a inexistência de uma "linguagem articulada" na criança que se encontra na primeira infância, o conflito e os impasses assumem normalmente uma perspectiva mais direta, na qual a criança, sem condições de negociar argumentativamente, coloca-se na posição simples e direta de mando ou obediência. Como afirma Rousseau (OC IV 261; 1992, p. 24), "suas primeiras idéias são de império ou de servidão”. A educação pelas coisas é característica de um período de desenvolvimento da criança no qual a autonomia, entendida como capacidade de pensar e decidir por conta própria, com base em argumentos racionais, está ausente e, nesta circunstância, a educação argumentativa não tem o mesmo poder de esclarecimento e convencimento como tem os exemplos extraídos da simples funcionalidade das coisas, com seus respectivos riscos, possibilidades e proibições.

Neste contexto, fica evidente que um comportamento inadequado do adulto em relação à criança e um exercício equivocado de seus 
cuidados podem torná-la, ao mesmo tempo, escrava e tirana. Rousseau refere-se claramente a isso na seguinte passagem do primeiro livro do Émile:

Finalmente, quando esta criança, escrava e tirana, cheia de conhecimentos e desprovida de sentidos, igualmente débil de corpo e de alma, é jogada no mundo mostrando a sua inépcia, seu orgulho e todos os seus vícios, ela faz com que se deplorem a miséria e a perversidade humanas. (OC IV 261; 1992, p. 24)

Uma postura inadequada do adulto para com a criança contribui decisivamente com a formação de seu caráter viciado, o qual, em vez de se contrapor ao egoísmo e à perversidade humana, assume-os como seus valores constitutivos. Uma intervenção discursiva vertical e excessiva na primeira infância corrompe a criança, tornando-a escrava e tirana, cuja combinação afasta-a de si mesma, gerando problemas sérios na constituição de sua identidade e, com isso, à sua socialização adulta futura.

No entanto, quanto mais a socialização da criança avança, mais a educação pelas coisas deve ceder lugar à educação discursiva, baseada no contrato e na negociação. Embora a educação discursiva inicie ainda na segunda infância e na adolescência, ela ocupará o centro do conceito rousseauniano de educação na fase da juventude, a qual é designada por Rousseau como idade da razão. Nesta fase, a educação natural cede, pouco a pouco, o lugar para a educação social.

No entanto, mesmo havendo um deslocamento claro no conceito de educação, do predomínio das coisas à centralidade do contrato baseado na negociação discursiva permanente entre os envolvidos no processo pedagógico, o fato é que Rousseau mantém, como válida, para qualquer uma das fases do processo educacional, a tese de que é a socialização e, portanto, a convivência da criança com o mundo adulto que a faz desenvolver sentimentos morais opostos, como o egoísmo, a raiva, a piedade e a cooperação. É por meio do indispensável confronto com outras vontades humanas que ela é estimulada a buscar seu equilíbrio, aprendendo a ser paciente ou a assumir atitudes opostas, de irritação e impaciência. Assim afirma ele (OC IV 287; 1992, p. 47): "Enquanto as crianças só experimentam resistência nas coisas e não em vontades estranhas, não se tornaram emburradas, nem coléricas, mas permanecerão com saúde". 
Se a resistência advinda do confronto com as coisas torna o corpo da criança saudável, por si só não é suficiente para constituir sua moralidade, a qual se origina do confronto entre vontades que não se reduzem à "lógica de funcionamento" das coisas. Sem a possibilidade de se tornarem "emburradas e coléricas" as crianças não se colocariam o problema do bem e do mal e, sem este, estariam alheias ao próprio problema da moralidade. Rousseau parece ter clareza sobre este ponto e, em todo caso, o que quer assegurar, como núcleo da formação da criança, em sua primeira infância, uma vez que nesta fase não se deve introduzi-la ainda, diretamente, nos princípios da moralidade, é a formação saudável de seu corpo e o desenvolvimento de sua sensibilidade por meio da educação pelas coisas.

O que a educação pelas coisas visa é a educação da vontade da criança. Entretanto, se a vontade da criança precisa ser educada, por outro lado, ela também precisa ser deixada a se desenvolver livremente, e o problema consiste justamente em saber quando ela deve ser regulada pela intervenção do adulto e quando deve ser deixada a se desenvolver livremente. Rousseau não dá evidentemente uma resposta pronta para este problema, mas parece oferecer um critério ao afirmar que também o adulto precisa, em determinadas circunstâncias, deixar dobrar-se a certas vontades da criança, sem precisar contrariá-la. Como afirma, "cumpre pensar sempre que há grande diferença entre lhes obedecer e não as contrariar" (idem, ibid.). Obedecer sem contrariála significa, neste contexto, atender aquelas necessidades que vão ao encontro da natureza e aos reclames da criança, que estão profundamente enraizados, por um lado, nas necessidades físico-biológicas e, por outro, no sentimento natural de justiça e de injustiça que reside em seu coração. Portanto, se, ao exercer seus cuidados para auxiliar a criança a satisfazer suas necessidades, o adulto simplesmente impusesse sua vontade, sem considerar o mundo da criança, ele certamente a estaria adestrando.

Por outro lado, se é da fragilidade inicial da criança, que brota de sua incapacidade de satisfazer por si mesma suas necessidades e, por isso, forma-se nela o sentimento de sua dependência em relação ao adulto, quando tais necessidades não forem atendidas adequadamente, elas podem se tornar um império de dominação. O domínio que a criança pode exercer sobre o adulto, tornando-o escravo dela e de si mesmo, depende muito mais dos cuidados por ele dispensados do que 
das necessidades naturais da própria criança. Rousseau parte da tese, portanto, de que a dominação escravizante assumida pela criança origina-se do próprio modo da intervenção adulta. Neste sentido, para que possa respeitar o mundo da criança, não a vendo apenas como um "pequeno adulto defeituoso", o adulto não pode simplesmente impor sua vontade a ela ou, por outro lado, dispor-se a atender todos seus caprichos.

Com isso, fica claro também que a dimensão significativa do conteúdo da educação natural deriva-se da exigência, posta ao adulto, de assumir responsabilidades na formação da vontade e do caráter da criança, não podendo, com isso, simplesmente projetar sua vontade no mundo da criança, mas, ao mesmo tempo, não manter intocável seus desejos e caprichos. Neste contexto, os efeitos morais observados no desenvolvimento da criança devem-se à sua socialização e, sobretudo em sua fase inicial, ao modo como o adulto intervém no mundo da criança. É por esta razão que Rousseau considera a moralidade não como obra da natureza, nem do destino e muito menos de forças divinas, mas sim como resultado das interações sociais. Daí brota a tese de que a moralidade das ações humanas está vinculada ao seu processo formativo-educacional e, portanto, ao seu próprio processo de socialização (Dalbosco, 2007b, p. 135-150).

Até aqui busquei mostrar a importância concedida pelo genebrino à intervenção do adulto no mundo da criança. Antes de prosseguir com a argumentação sobre tal importância, ressaltando outros aspectos, torna-se oportuno voltar-se à objeção posta no início do ensaio, reformulando-a agora por meio da seguinte pergunta: Ao conceder tal importância à intervenção do adulto, Rousseau estaria se distinguindo realmente da pedagogia moralista de sua época? Penso que o que o diferencia daquela é o modo como compreende os cuidados do adulto e o conteúdo que lhes atribui. Rousseau é um dos primeiros, entre os modernos, a expor a tensão constitutiva do processo pedagógico que emerge do ideal de autonomia e de emancipação atribuído aos envolvidos e faz isso quando, ao pensar especificamente no papel do adulto, indica o grau de complexidade presente em sua relação com a criança, mostrando que a tarefa adulta movimenta-se no fio da navalha de não adestrar a criança e nem se deixar ser por ela escravizada.

Sua posição sobre este problema é enunciada na seguinte passagem: "É importante acostumá-la desde cedo a não comandar nem nos 
homens, pois não é seu senhor, nem nas coisas porque não a escutam" (OC IV 287-288; 1992, p. 48). Mas o que resta à criança - poderíamos nos perguntar, a esta altura da argumentação - se ela não pode comandar nem os homens e nem as coisas? Vê-se que o esforço de justificação da educação natural dirigida à infância exige a formação de um caráter que deve permitir à criança encontrar devidamente seu espaço entre os homens e as coisas, sem que destrua a ambos por meio de seu modo de agir e nem seja por eles aniquilada. A busca por este espaço precisa ser orientada, desde o início, e exatamente aí reside o problema, pela inserção progressiva da criança no "caldeirão" da sociabilidade ou no "inferno" das relações sociais.

$\mathrm{O}$ preceito da educação natural consiste em fazer com que a criança tire conclusôes a partir de sua idade e de acordo com suas condições e possibilidades sensitivo-racionais. Para Rousseau, as crianças não são "anjos" e nem "demônios", mas seres humanos em desenvolvimento e é o processo de socialização delas, por meio das mãos do adulto, que as torna o que são em sua primeira infância. O genebrino deixa claro, em muitas passagens do Émile, que, ao serem confrontadas com um comportamento inadequado do adulto, as crianças incorporam qualidades destrutivas ao seu caráter. $\mathrm{O}$ conteúdo da seguinte passagem confirma isso:

Assim elas se tornam incômodas, tirânicas, voluntariosas, maldosas, indomáveis; desenvolvimento que não lhes vem de uma vontade natural de domínio e sim que lhes dá essa vontade [do adulto, CAD.]; pois não é preciso uma longa experiência para sentir o quanto é agradável alcançar algo pela atividade de outrem e não ser preciso senão mexer a língua para colocar em movimento o universo. (OC IV 289; 1992, p. 167-168)

O paradoxo consiste no fato de que, em sua relação com as crianças, os adultos impõem-lhes, primeiro, sentimentos de dominação e de maldade e, depois, deixam-se escravizar a si próprios por tais sentimentos. A pergunta consiste, evidentemente, em saber por que a intervenção adulta toma esta direção: seria, nesta situação, um desejo claro de "preservação da espécie", uma vez que os pais, por exemplo, para poderem tornar seus filhos aptos a competirem socialmente, precisam fazer concessóes permanentes, dobrando-se aos desejos ilimitados da criança? Rousseau não desconecta a justificativa de seu projeto de educação natural da crítica cultural mais ampla, dirigida contra a sociedade 
de sua época, sendo que um de seus objetivos é evitar, neste contexto, que se reproduzam, na formação da criança, as mesmas formas de vida marcadas pelo cinismo e pela dissimulação, próprias à racionalidade da sociedade de corte (Elias, 1989), da qual ele próprio fora excluído em sua infância e juventude e na qual participou por algum tempo de sua vida adulta, para depois retirar-se quase inteiramente dela.

\section{O caminho natural de educação da criança: marche de la nature}

Antes de prosseguir, resumamos o aspecto importante do que foi dito até aqui: temos, como núcleo da caracterização atribuída por Rousseau aos cuidados do adulto, a insistência na proteção da criança contra o excesso da intervenção discursiva do adulto, recorrendo à educação pelas coisas como modelo normativo para regular o exercício adulto dos cuidados. Se seu argumento terminasse aí, certamente a análise pedagógica do filósofo genebrino sobre a primeira infância permaneceria muito incompleta. No entanto, ele acrescenta um terceiro e decisivo argumento para precisar os cuidados do adulto, a saber, a exigência de conduzir a criança ao seu caminho natural, concebendo-o como princípio pedagógico da educação pelas coisas.

Mas o que significa propriamente caminho natural como especificação pedagógica da educação pelas coisas? Embora seu significado seja central à qualificação dos cuidados do adulto, a expressão "caminho natural" parece mais confundir do que ajudar, considerando seu caráter enigmático. Reconstruir seu significado não é tarefa fácil, porque, considerando a tese forte da teoria social de Rousseau, trata-se da "naturalidade" de um processo que só pode ser conquistado mediante a socialização da criança. Por caminho natural entende Rousseau, primeiro, o desenvolvimento das disposições naturais em oposição aos vícios e isso significa dizer que toda educação e todos os cuidados a ela dispensados devem estar orientados para atender, de modo não viciado, as necessidades naturais da criança. Isto é, o adulto deve contribuir para não torná-la dependente, egoísta e dominadora.

Em segundo lugar, o significado do caminho natural repousa na diferença entre as necessidades e as fantasias que constituem o mundo da criança. A passagem da necessidade à fantasia é algo que deve ser observado atentamente pelo adulto, pois a forma elementar e grosseira 
de corrupção do caráter de ambos começa quando o adulto não está preparado o suficiente para perceber o quanto a criança é capaz não só de fantasiar seu mundo, mas, principalmente, para empregar de forma habilidosa tal fantasia na conquista de seus desejos e caprichos desregrados. Portanto, o cuidado do adulto mostra-se aqui como sua capacidade de perceber adequadamente a diferença entre necessidade e fantasia e, ao mesmo tempo, poder disciplinar, de modo não autoritário, a corrupção do desejo infantil em fantasias cheias de capricho. Mas o que constitui a necessidade e a fantasia e no que elas se diferenciam propriamente?

Muitas dificuldades estão associadas a esta distinção. No que diz respeito, especificamente, ao conceito de necessidade, é preciso considerar que, como vimos, seu significado não pode ser esclarecido somente com o recurso aos aspectos fisiológicos e biológicos que o compóem, como, por exemplo, as necessidades elementares de sobrevivência (satisfação da fome, da sede, do sono etc.), mas, e sobretudo, às disposiçôes naturais e o seu desenvolvimento como condição indispensável à socialização humana. Juntamente com a supressão das necessidades básicas, coloca-se o desenvolvimento das disposiçôes naturais. Ora, os cuidados do adulto, para poderem conduzir adequadamente à criança ao seu caminho natural, precisam atender estas duas exigências.

Em relação à fantasia, por sua vez, sua definição não é tão simples como poderia parecer, porque está muito próxima da imaginação, à qual Rousseau, como sabemos, atribui papel decisivo na formação moral de Emílio: é por meio da imaginação que Emílio adquire a capacidade de sair de si mesmo, rompendo com o egoísmo de seu amor próprio e deixando-se compadecer pelo sofrimento do outro. O ponto importante nesta discussão é que tanto a fantasia como a imaginação, embora não sejam idênticas, precisam contar com certo grau de espontaneidade criativa, que se torna um fator comum entre ambas. Ora, a questão decisiva, para o exercício adequado dos cuidados do adulto, é como ele pode limitar a capacidade fantasiosa da criança orientada por "desejos caprichosos" sem que coíba o desenvolvimento daquela capacidade imaginativa que é indispensável à sua formação moral.

Apesar destas dificuldades, os cuidados do adulto precisam estar voltados à tarefa de conduzir a criança ao caminho natural. Rousseau formula, em quatro máximas, o modo e o sentido como o adulto pode ajudá-la a manter-se no caminho da natureza: 
Primeira: ajudar a criança a desenvolver e empregar livremente todas as forças que recebeu da natureza, evitando também que abuse das mesmas.

Segunda: auxiliá-la a suprir todas suas necessidades físicas e suas carências relacionadas à inteligência e à força.

Terceira: limitar os cuidados no trato com a criança ao "útil real", não concedendo nada, sem razão, à sua fantasia e ao seu desejo.

Quarta e última máxima: observar com atenção e cuidado a linguagem e os sinais da criança para poder distinguir, através deles, o que nos desejos dela vem da natureza e o que é imediatamente provindo da opinião e da artificialidade do mundo adulto.

Em síntese, o conteúdo destas máximas prescreve um procedimento cuidadoso do adulto em relação ao mundo da criança, devendo tal procedimento auxiliar na supressão das necessidades físicas, no desenvolvimento das forças naturais, no disciplinamento da fantasia e do desejo da criança e, por meio da observação de seu choro, de seu gesto e de sua linguagem, rejeitar firmemente opiniôes e desejos provindos da artificialidade do mundo adulto. $\mathrm{O}$ sentido preciso contido por estas máximas atribui, portanto, um conteúdo claramente ético-pedagógico aos cuidados do adulto para com as necessidades da criança. Com o estabelecimento destas máximas e com as exigências postas ao tipo de cuidado que o adulto precisa exercer, Rousseau visa fortalecer um núcleo interno de resistência da criança contra a "invasão perversa" da sociedade: como não se pode educar a criança no isolamento e como ela ainda não está em condições, em sua primeira fase de vida, de distinguir entre o bem e o mal e, por isso, como ela está extremamente dependente dos cuidados do adulto, pensar um projeto de educação natural para esta primeira fase implica dedicar um "cuidado especial" ao modo como o adulto dispensa seus cuidados às crianças. Nesse sentido, o projeto da educação natural de Rousseau pode ser compreendido como um cuidar do próprio cuidado (Dalbosco, 2007a, p. 187-206).

\section{Da educação pelas coisas à liberdade bem regrada}

Se as máximas formuladas acima são suficientes ou não para manter a criança no caminho da natureza, permanece como uma questão em aberto. De qualquer modo, elas têm como propósito, segundo 
a intenção de Rousseau, garantir um dos princípios da educação natural, a saber, o de contribuir na formação da criança como "rainha de si mesma” e isso exige, por sua vez, introduzi-la no conceito de liberdade bem regrada. Afirma Rousseau:

O espírito destas regras consiste em conceder às crianças mais liberdade verdadeira e menos voluntariedade, em deixar com que façam mais por si mesmas e exijam menos dos outros. Assim, acostumando-se, desde cedo, a subordinar seus desejos a suas forças, elas sentirão pouca privação do que não estiver em seu poder. (OC IV 290; 1992, p. 50).

O conteúdo da educação natural expressado nesta passagem exige, de modo claro, um equilíbrio na formação da criança, que não prime nem pela falta e nem pelo excesso, mas vise sua autodeterminação progressiva, a qual pressupõe um autodomínio mínimo em relação aos seus desejos, uma consciência serena em relação aos seus limites e, por fim, um exercício adequado de sua própria liberdade.

A liberdade bem regrada é o quarto argumento arrolado por Rousseau para definir os cuidados do adulto em relação à criança, servindo com isso também para ampliar a própria definição de primeira infância. Para que não seja compreendido como um caminho de volta à natureza enquanto exclusão da sociabilidade humana, o próprio caminho da natureza precisa ser completado pelo significado da expressão liberdade bem regrada, impondo limites e condiçôes ao modo como os cuidados adultos devam ser exercidos. Ou, melhor dito, a idéia de liberdade bem regrada deve servir como ideal normativo regulador do princípio pedagógico de condução da criança ao caminho da natureza e, frente a isso, do modo como o adulto exerce seus cuidados. A tensão que cruza o significado da expressão "liberdade bem regrada", entre os dois valores absolutos, a liberdade e a lei, projeta uma complexidade elevada ao exercício dos cuidados. Ou seja, o princípio de maioridade - o "tornar a criança rainha de si mesma" - pressupõe a liberdade, a qual, sem a referência a regras mínimas, torna-se completamente cega, egoísta e autodestrutiva. Mas o problema consiste, do ponto de vista pedagógico, em como manter a liberdade mediante o caráter minimamente coercitivo imposto por qualquer regra. Se ao cuidado do adulto é exigido que não perca de seu horizonte tanto a liberdade como a lei, o desafio que se apresenta é o de como tornar produtiva, no processo pedagógico, a tensão entre liberdade e lei, sobretudo, considerando-se 
o fato de que a situação da criança, em sua primeira infância, ainda não lhe oferece condições sequer de se aperceber adequadamente de tal conflito.

Tal desafio põe um questionamento claro sobre o modo como o adulto deve exercer seus cuidados: como contribuir para a liberdade da criança, visando sua autonomia, sabendo que a conquista da mesma exige o confronto da ação da criança com o caráter coercitivo mínimo das regras, em uma situação na qual a própria criança ainda não está em inteiras condições de compreender racionalmente o conteúdo das regras? $\mathrm{O}$ que se pode e deve ser imputado à sua ação? $\mathrm{O}$ dilema consiste no fato de que, se, por um lado, a rigidez extremada das regras conduz ao adestramento, por outro, sua flexibilização excessiva leva ao espontaneísmo anárquico e, com ele, à insociabilidade humana. Eis novamente o fio afiadíssimo de uma navalha sobre o qual deve se movimentar, segundo os preceitos da educação natural, o cuidado adulto dispensado à supressão das necessidades da criança. Neste contexto, socializar não adestrando torna-se o lema da educação natural.

\section{O caráter aporético da educação natural}

Conduzir a criança no caminho da natureza, orientado pela idéia da liberdade bem regrada, constitui o ideal normativo regulador do modo como o adulto deve exercer seus cuidados em relação às necessidades da criança, em sua primeira infância. Orientando sua ação pela busca de tal ideal, o adulto estaria respeitando a criança em seu próprio mundo. Se este é o resultado principal das análises precedentes, quero mostrar agora, em forma de conclusão, em que sentido tal resultado está profundamente dependente do caráter aporético da educação natural.

Usei até aqui, indistintamente, o conceito de aporia. Convém agora, antes de avançar na análise, esclarecer seu sentido mais apropriado para caracterizar o projeto da educação natural. Em um de seus significados gregos, a aporia provém da dificuldade experimentada pelo emprego conflituoso de argumentos (Aristóteles, Tópicos, II, 145b, p. 138ss). Neste significado está explícita a idéia de que uma argumentação aporética é logicamente contraditória e, por sêla, conduz os argumentos a um caminho sem saída, tornando-os deste modo inválidos. Mas aporia pode significar também o contorno 
argumentativo de dificuldades insolúveis, sem que a análise chegue a um termo definitivo. É este segundo significado que interessa ao tema que está sendo tratado, pois abre a possibilidade para se compreender o discurso filosófico sobre o processo formativo-educacional humano e, no contexto especificamente de Rousseau, o discurso acerca do modo como o adulto exerce seus cuidados, como um discurso que não pode alcançar uma conclusão definitiva.

Considerando isso, o caráter aporético do projeto da educação natural reside na tentativa de contornar dificuldades insolúveis que se apresentam no processo da relação pedagógica entre adulto e criança. Para esclarecer isso, quero evidenciar agora o nexo entre os quatro argumentos que caracterizam o modo dos cuidados do adulto e o pólo tensivo que emerge de cada um deles. Sendo assim, temos, no que diz respeito ao primeiro argumento, que, do modo como a mãe se relaciona com o bebê e, em sentido mais amplo, do modo como o adulto se relaciona com a criança, emerge a tensão entre o caráter indispensável de seus cuidados no atendimento às necessidades da criança e o risco eminente de viciar o comportamento da criança por meio do exercício de tais cuidados. Na seqüência, do segundo argumento, que consiste no princípio pedagógico da educação pelas coisas, e do terceiro, que põe o caminho natural como especificação da educação pelas coisas, surge a tensão entre o desenvolvimento das disposições naturais e o recurso à arte da encenação. A ela vincula-se também a questão decisiva à educação natural: Como pode ser realmente "natural", no sentido normativo mais forte que o termo assume em Rousseau, o exercício dos cuidados do adulto que, ao mesmo tempo em que se baseia no caminho natural da educação pelas coisas, também precisa recorrer à arte da encenação? Por fim, do quarto argumento, que se refere à idéia da liberdade bem regrada, emerge a tensão entre o cultivo da liberdade e o caráter coercitivo da regra.

No que diz respeito ao primeiro, a análise precedente mostrou que as necessidades da criança não podem ser atendidas sem os cuidados do adulto e que estes cuidados, por ser um modo prático-social do adulto viver no mundo, não estão isentos da perversão, do cinismo e da corrupção reinantes na sociedade. Com isso, fica evidente o aspecto do caráter aporético do projeto de educação natural dirigido à primeira infância: sem os cuidados do adulto a criança não sobreviveria e, ao 
depender deles, não está livre de incorporar seus hábitos viciosos. O dilema consiste aqui no fato de que a satisfação das necessidades da criança e, portanto, a manutenção de sua própria sobrevivência dependem de seu contato com os hábitos viciados do adulto.

O segundo pólo tensivo da aporia emerge do princípio pedagógico da educação pelas coisas e, mais precisamente, de sua vinculação com a arte da encenação. Rousseau recorre a ela em muitas passagens do Émile para trazer seu aluno fictício para dentro dos princípios da educação natural: encena e simula situaçōes para provar e reforçar o caráter do Emílio. No entanto, um dos problemas que se coloca aí é o de saber até onde a encenação corresponde efetivamente aos princípios da educação natural e quando a própria arte da encenação não se transformaria em uma criação artificial e meramente dissimuladora do educador. A aporia consiste no fato de que a educação natural precisa recorrer, por um lado, a um mecanismo artificial para fazer valer seu princípio de livre desenvolvimento das disposições naturais do aluno, sem ter, por outro, garantia sobre a legitimidade pedagógica e moral de tal mecanismo: visando uma educação natural, busca-se combater o artificialismo por meio de um recurso artificial! Esta dificuldade inerente ao princípio pedagógico da educação pelas coisas põe, como se vê, outros problemas ao esforço rousseauniano de elaborar princípios à educação da criança na primeira infância que enfatizem mais o exemplo do educador do que suas intervenções autoritárias, manifestadas tanto pela agressão física como pela ação verbal ríspida. Enfim, ela exige uma reavaliação constante da arte da encenação como recurso pedagógico para manter a criança no caminho da natureza. $\mathrm{O}$ governante (pedagogo) precisa ter consciência clara de que a educaçáo da infância não se faz sem o recurso a arte da encenação, a qual, por sua vez, tem seus próprios limites.

O terceiro pólo tensivo emerge do confronto entre as vontades dos envolvidos no processo pedagógico. Embora a oposição do comportamento da criança à resistência das coisas seja o melhor procedimento à formação segura e digna de seu caráter, tal oposição só pode se realizar no processo de socialização, o qual implica a oposição entre vontades, a da criança e a do adulto. Isso mostra que o conteúdo da educação natural, mesmo quando pensado à primeira infância, só pode ser definido por meio do confronto entre vontades humanas que são 
diferentes entre si. O que está implícito, no fundo, é a tese de que uma educação adequada da vontade da criança constitui um núcleo decisivo para seu desenvolvimento moral e a questão é que tal vontade só pode ser educada mediante o conflito permanente entre a liberdade e a existência de leis. Como vimos, o princípio pedagógico de condução da criança pelo caminho da natureza só assume sua inteira significação pedagógica quando inserido no ideal normativo da liberdade bem regrada. Tal inserção evidencia, por sua vez, o conflito crucial entre liberdade e lei que cruza o processo pedagógico do começo ao fim, revelando à educação um de seus maiores desafios: Como educar para a liberdade mediante o caráter coercitivo mínimo imposto por qualquer regra?

Parece-me, neste contexto, que a idéia de liberdade bem regrada reúne, como ideal normativo da educação natural, os principais aspectos da tentativa desesperada de Rousseau de contornar as dificuldades insolúveis que surgem da busca pela relação humanamente pedagógica entre adulto e criança.

\section{Recebido em agosto de 2008 e aprovado em dezembro de 2008.}

\section{Notas}

1. Como não posso tratar aqui da obra Émile em sua totalidade, indico, para uma visão panorâmica geral, os trabalhos já clássicos de Ritzel (1959) e Forschner (1977). No entanto, para uma interpretação mais recente, é sugestivo consultar a pesquisa de Sturma (2001).

2. Sob este aspecto, Rousseau antecipa muito do que Winnicott (2002, p. 1-13) atribuirá como papel insubstituível da mãe como "ambiente facilitador".

3. (1992, p. 21; 2004, p. 125). Todas as citações das obras de Rousseau, salvo indicação contrária, serão feitas como a que seguiu, indicando-se no corpo do próprio texto, de acordo com a edição Gallimard da Bibliothèque de la Plêiade, a abreviatura oc, referente às Oeuvres Completes, seguida da indicação do volume em romano maiúsculo e com a respectiva paginação em arábico. A indicação da fonte francesa será seguida, imediatamente, pela indicação do ano e da página da tradução portuguesa, na qual me amparei, modificando-a quando julguei necessário.

4. Os ideais de uma educação natural podem ser vertidos, neste sentido, contra o aspecto "alienante" do mundo adulto, compreendido como "espetáculo". Em seu penetrante estudo, Salinas Fortes (1997) procurou mostrar a centralidade do conceito de espetáculo, bem como de seu caráter ambíguo, no pensamento de Rousseau, o qual conceberia o espetáculo como categoria constitutiva da necessidade humana imperiosa de mostrar-se ao outro, assumindo a função de um elo que ataria o "eu" ao "outro". 
Referências

ARISTÓTELES. Philosophische Schriften in sechs Bänden. Hamburg: Meiner, 1995. v. 2.

DALBOSCO, C.A. Pedagogia filosófica: cercanias de um diálogo. São Paulo: Paulinas, 2007a.

DALBOSCO, C.A. Determinação racional da vontade humana e educação natural em Rousseau. Educação \& Pesquisa, São Paulo, v. 33, n. 1, p. $135-150,2007 \mathrm{~b}$.

ELIAS, N. Die Höfische Gesellschaft. Frankfurt am Main: Suhrkamp, 1989.

FORSCHNER, M. Rousseau. Freiburg: Karl Alber, 1977.

FORSCHNER, M. Über das Handeln im Einklag mit der Natur. Darmstad: WBG, 1998.

RITZEL, W. Jean-Jacques Rousseau. Stuttgart: W. Kohlhammer, 1959. ROUSSEAU, J.J. Oeuvres complètes. Paris: Gallimard, 1959-1995. 5v.

ROUSSEAU, J.J. Emilio ou Da educação. Rio de Janeiro: Bertrand Brasil, 1992.

SALINAS FORTES, L.F. Paradoxo do espetáculo: política e poética em Rousseau. São Paulo: Discurso, 1997.

STURMA, D. Jean-Jacques Rousseau. München: Beck, 2001.

WINNICOTT, D. Os bebês e suas mães. São Paulo: Martins Fontes, 1999. 